\title{
Philippe Jaccottet - Gustave Roud, Correspondance 1942-1976
}

\section{Maurizio Nascimbene}

\section{(2) OpenEdition}

1 Journals

\section{Edizione digitale}

URL: https://journals.openedition.org/studifrancesi/46285

DOI: 10.4000/studifrancesi.46285

ISSN: 2421-5856

\section{Editore}

Rosenberg \& Sellier

\section{Edizione cartacea}

Data di pubblicazione: 1 octobre 2007

Paginazione: 477

ISSN: 0039-2944

\section{Notizia bibliografica digitale}

Maurizio Nascimbene, «Philippe Jaccottet - Gustave Roud, Correspondance 1942-1976», Studi Francesi [Online], 152 (LI | II) | 2007, online dal 30 novembre 2015, consultato il 24 novembre 2021. URL: http:// journals.openedition.org/studifrancesi/46285 ; DOI: https://doi.org/10.4000/studifrancesi.46285

Questo documento è stato generato automaticamente il 24 novembre 2021.

\section{(c) (i) (9)}

Studi Francesi è distribuita con Licenza Creative Commons Attribuzione - Non commerciale - Non opere derivate 4.0 Internazionale. 


\title{
Philippe Jaccottet - Gustave Roud, Correspondance 1942-1976
}

\author{
Maurizio Nascimbene
}

\section{NOTIZIA}

PHILIPPE JACCOTTET - GUSTAVE ROUD, Correspondance 1942-1976, a cura di José-Flore TAPPY, Paris, Gallimard, 2002, pp. 553.

1 L'opera voluta e approvata dallo stesso Jaccottet dopo la morte di Roud, e curata da José-Flore Tappy, collaboratrice del Centre de recherches sur les lettres romandes dell'Università di Losanna, rappresenta un capitolo fondamentale all'interno della bibliografia dei due poeti svizzeri, ma soprattutto fornisce un prezioso strumento lavorativo a tutti gli studiosi di Philippe Jaccottet. La cernita delle lettere tra questi e il suo maestro-amico-collega Gustave Roud getta nuova e importante luce sull'attività saggistica e di traduzione di Jaccottet, e mostra con quale intensità egli abbia meditato e discusso su ogni progetto. Dopo le undici lettere giovanili dei due poeti, scritte tra il 1943 e il 1947 e apparse nell'autunno 1992 nella rivista losannese «Écriture 40», e dopo le tre del 1965 uscite a Meaux, nella primavera 1997, presso i tipi della rivista "Conférence», questa Correspondance disegna il più esaurientemente possibile sia il Philippe Jaccottet studioso - parte, questa, che s'impone come il corpo più sostanzioso del volume della Tappy sia il Philippe Jaccottet uomo (capace di incantarsi durante una passeggiata notturna; felice per la nascita dei suoi figli; preoccupato per la mole di lavoro affidatagli; e vero amico di uno scrittore, quale è stato Roud, attraversato qua e là da crisi lavorative. Ma la Correspondance curata dalla Tappy non è solo questo: attentamente studiata e preceduta da un'efficace prefazione, ci dona lettere capitali per ricostruire una certa letteratura svizzera contemporanea forse troppo dimenticata, ma che in queste pagine non direttamente, ma di riflesso lascia intravedere il proprio non trascurabile ruolo all'interno di una cultura novecentesca europea in fase di crescita. A 
completare il tutto, un testo di Jaccottet datato 14 novembre 1952 e restato inedito: Le Tournesol. 